\title{
EDITORIAL
}

\section{In focus in HCB}

\author{
Douglas J. Taatjes ${ }^{1}$ (D) Jürgen Roth ${ }^{2}$
}

Accepted: 16 January 2017 / Published online: 1 March 2017

(C) Springer-Verlag Berlin Heidelberg 2017

There are multiple ways to assess the overall impact of a scientific article, and this is a matter of ongoing discussion (Callaway 2016; Hicks et al. 2015). The number of times an article has been downloaded as a pdf and read may provide an informative snapshot in this regard. The volume 145 of Histochemistry and Cell Biology consisted of six issues, comprising 49 articles, published between January and June 2016. By establishing a somewhat subjective criterion of "highly read" representing an article whose pdf was downloaded $\geq 400$ times, $29 \%$ of the articles published in volume 145 fell into this category (Table 1); the remaining $71 \%$ of articles were downloaded between 100 and $<400$ times.

Here, we will briefly highlight the findings of four articles appearing in the current issue. Spiral ganglion neurons (SGN), which transmit auditory signals from the cochlear to the brain, are essential components of normal hearing. Since high mobility group box 1 protein (HMGB1) was recently shown to regulate epithelial reorganization of the organ of Corti after hair cell loss induced by treatment with the aminoglycoside antibiotic amikacin (Ladrech et al. 2013), Ladrech and colleagues (2017) have now investigated whether HMGB1 may also be involved in mediating early stress responses in SGNs. They found that HMGB1 and p-c-Jun (an activated form of an early stress-activated transcription factor) accumulated in the nuclei of the SGNs (see journal cover image), while BCL2 (an indicator of

Douglas J. Taatjes

douglas.taatjes@uvm.edu

1 Department of Pathology and Laboratory Medicine, The University of Vermont College of Medicine, Burlington, VT 05405, USA

2 University of Zurich, 8091 Zurich, Switzerland apoptosis) was found over-expressed in the cytoplasm during neuronal recovery from amikacin-induced structural damage. The authors speculate that HMGB1 may act in allowing enhanced access for p-c-Jun to nuclear DNA, perhaps thus promoting activation of transcription factors involved in cell repair mechanisms.

It is well established that during the first trimester of pregnancy, extravillous trophoblasts (EVTs) not only migrate and invade the decidual interstitium serving to anchor the placenta to the uterus, they also modify the spiral arteries during this invasion; however, whether EVTs in a likewise manner invade and modify uterine veins has not been definitively determined. Moser et al. (2017) have now addressed this question using stereological principles combined with serial section immunohistochemistry to differentiate between arteries and veins. Most interestingly, and perhaps surprisingly, this very elegant and careful evaluation showed that uterine veins are actually significantly more invaded by ETVs than uterine arteries during early pregnancy. This is a most striking finding and may potentially represent a paradigm shift in the area of placental teaching and research. The authors speculate that the EVT invasion of uterine veins during the first trimester of pregnancy may serve in the draining of waste materials and blood plasma from intervillous spaces.

Ephrin receptors and Ephrin ligands are important for cell adhesion and migration. Konda et al. (2017) investigated the potential role the Ephrin receptor EphA2 and the Ephrin ligand ephrin-A1 play in mouse spleen for macrophage/monocyte immigration and emigration. Both EphA2 and ephrin-A1 were found to be predominantly expressed in the vascular endothelial cells of the marginal zone and the red pulp. A monocyte/macrophage cell line expressing an EphA2 lacking the kinase domain was used for in vivo cell infiltration assays. These results indicated 
Table 1 Article impact assessed as number of pdf downloads ( $n)$

\begin{tabular}{ll}
\hline$n$ & Article \\
\hline 2100 & Vidak and Foisner: Molecular insights into the premature aging disease progeria \\
995 & Weipoltshammer and Schöfer: Morphology of nuclear transcription \\
988 & Buttler et al.: Integration of CD45-positive leukocytes into newly forming lymphatics of adult mice \\
746 & Kristó et al.: Actin, actin-binding proteins, and actin-related proteins in the nucleus \\
670 & Yu et al.: Expression of area-specific M2-macrophage phenotype by recruited rat monocytes in duct-ligation pancreatitis \\
568 & Podlasz et al.: Galanin regulates blood glucose level in the zebrafish: a morphological and functional study \\
516 & Chen et al.: A novel interaction between ATOH8 and PPP3CB \\
506 & Smirnov et al.: Nucleolar DNA: the host and the guests \\
487 & Sun et al.: Pharmacokinetic and pharmacometabolomic study of pirfenidone in normal mouse tissues using high mass resolution \\
416 & MALDI-FTICR-mass spectrometry imaging \\
404 & André et al.: Merging carbohydrate chemistry with lectin histochemistry to study inhibition of lectin binding by glycoclusters in the \\
& Zhatural tissue context \\
402 & of collagen IV \\
400 & Abrastoo et al.: Phospholipase C- $\eta 2$ interacts with nuclear and cytoplasmic LIMK-1 during retinoic acid-stimulated neurite growth \\
& osteoclasts \\
400 & Yamazaki et al.: Nuclear F-actin enhances the transcriptional activity of $\beta$-catenin by increasing its nuclear localization and binding to \\
& chromatin
\end{tabular}

Articles published between January and June 2016. Number of pdf downloads as per 31 December 2016

that the EphA/ephrin-A system regulates transendothelial migration, infiltration, and lodgment of monocytes/macrophages in the red pulp of the spleen and that the truncated EphA2 enhances this process.

Dentin matrix protein1 (Dmp1) is an acidic phosphoprotein of osteocytes proposed to participate in bone and dentin mineralization. Dmp1 becomes proteolytically cleaved by PHEX protein in $\mathrm{N}$ - and C-terminal fragments, the latter being phosphorylated and considered to be the functional domain. Oya et al. (2017) report now that C-terminal Dmp1 becomes phosphorylated by Fam20C in the Golgi apparatus of osteoblast, osteoid, and young osteocytes present in the superficial bone layer and afterwards is secreted into the pericanalicular matrix of mineralized bone. Here, at the mineralization front, it may initiate hydroxyapatite formation and may be involved in collagen matrix mineralization.

\section{References}

Abdelgawad ME, Delaisse JM, Hinge M et al (2016) Early reversal cells in adult human bone remodeling: osteoblastic nature, catabolic functions and interactions with osteoclasts. Histochem Cell Biol 145:603-615

André S, Kaltner H, Kayser K et al (2016) Merging carbohydrate chemistry with lectin histochemistry to study inhibition of lectin binding by glycoclusters in the natural tissue context. Histochem Cell Biol 145:185-199

Arastoo M, Hacker C, Popovics P et al (2016) Phospholipase C- $\eta 2$ interacts with nuclear and cytoplasmic LIMK-1 during retinoic acid-stimulated neurite growth. Histochem Cell Biol 145:163-173

Buttler K, Lohrberg M, Gross G et al (2016) Integration of CD45positive leukocytes into newly forming lymphatics of adult mice. Histochem Cell Biol 145:629-636

Callaway E (2016) Publishing elite turns against impact factor. Nature 535:210-211

Chen J, Balakrishnan-Renuka A, Hagemann N et al (2016) A novel interaction between ATOH8 and $\mathrm{PPP}_{3} \mathrm{CB}$. Histochem Cell Biol (2016) 145: 5-16

Hicks D, Wouters P, Waltman L, de Rijke S, Rafols I (2015) The Leiden Manifesto for research metrics. Nature 520:429-431

Konda N, Saeki N, Nishino S, Ogawa K (2017) Truncated EphA2 likely potentiates cell adhesion via integrins as well as infiltration and/or lodgment of a monocyte/ macrophage cell line in the red pulp and marginal zone of the mouse spleen, where ephrin-A1 is prominently expressed in the vasculature. Histochem Cell Biol. doi:10.1007/s00418-016-1494-8

Kristó I, Bajusz I, Bajusz C et al (2016) Actin, actin-binding proteins, and actin-related proteins in the nucleus. Histochem Cell Biol 145:373-388

Ladrech S, Mathieu M, Puell JL (2013) Supporting cells regulate the remodelling of aminoglycoside-injured organ of Corti, through the release of high mobility group box 1 . Eur J Neurosci 38:2962-2972

Ladrech S, Wang J, Mathieu M et al (2017) High mobility group box 1 (HMGB1): dual functions in the cochlear auditory neurons in response to stress? Histochem Cell Biol. doi:10.1007/ s00418-016-1506-8

Moser G, Weiss G, Sundl M et al (2017) Extravillous trophoblasts invade more than uterine arteries: evidence for the invasion of uterine veins. Histochem Cell Biol. doi:10.1007/ s00418-016-1509-5

Oya K, Ishida K, Nishida $T$ et al (2017) Immunohistochemical analysis of dentin matrix protein 1 (Dmp1) phosphorylation by Fam20C in bone: implications for the induction 
of biomineralization. Histochem Cell Biol. doi:10.1007/ s00418-016-1490-z

Podlasz P, Jakimiuk A, Chmielewska-Krzesinska M et al (2016) Galanin regulates blood glucose level in the zebrafish: a morphological and functional study. Histochem Cell Biol 145:105-116

Smirnov E, Cmarko D, Mazel T et al (2016) Nucleolar DNA: the host and the guests. Histochem Cell Biol 145:359-372

Sun N, Fernandez IE, Wei M et al (2016) Pharmacokinetic and pharmacometabolomic study of pirfenidone in normal mouse tissues using high mass resolution MALDI-FTICR-mass spectrometry imaging. Histochem Cell Biol 145:201-211

Vidak S, Foisner R (2016) Molecular insights into the premature aging disease progeria. Histochem Cell Biol 145:401-417
Weipoltshammer K, Schöfer C (2016) Morphology of nuclear transcription. Histochem Cell Biol 145:343-358

Yamazaki S, Yamamoto K, de Lanerolle P et al (2016) Nuclear F-actin enhances the transcriptional activity of $\beta$-catenin by increasing its nuclear localization and binding to chromatin. Histochem Cell Biol 145:389-399

Yu E, Goto M, Ueta $\mathrm{H}$ et al (2016) Expression of area-specific M2-macrophage phenotype by recruited rat monocytes in ductligation pancreatitis. Histochem Cell Biol 145:659-673

Zhou Z, Pausch F, Schlötzer-Schrehardt U et al (2016) Induction of initial steps of angiogenic differentiation and maturation of endothelial cells by pericytes in vitro and the role of collagen IV. Histochem Cell Biol 145:511-525 